In Journal of Health Management, 7(2), 249-262. 2005

\title{
Integrating Traditional Services within Primary Health Care
}

\author{
Ajit K Dalal \\ University of Alahabad
}

\begin{abstract}
Abstact
This paper critically reviews the current status of primary health care services in India. It was observed that medical services have primary relied on western medicine, and are incompatible with the prevailing health beliefs and practices. The failure of western medicine, and as a consequence, that of primary health care calls for developing some culturally compatible health care models for India. The traditional health services which have existed for thousands of years and have wide acceptance and application throughout India need to be rejuvenated and integrated within the existing health care programmes. The possibilities of such hybrid services are explored in this paper to improve the quality of health and well-being of the masses.
\end{abstract}




\section{Integrating Traditional Services within Primary Health Care}

A recent story in The Washington Post narrated how 53-year-old Howard Staab travelled all the way from the United States to New Delhi's Escort Heart Institute and Research Centre for a surgical operation that saved him from a life-threatening heart problem. The procedure cost him $\$ 10,000$, a mere 5 per cent of the fee he would have had to pay back in the U.S. Staab is but one of the 150,000 foreigners who visited India last year seeking comparatively cheap medical solutions. "If we do this, we can heal the world," Apollo Hospitals' founder-chairman Dr. C. Prathap Reddy said. But who will heal the people of India, while the country waits for the crumbs from medical tourism, which is projected to grow into a $\$ 2.2$ billion industry by 2012 (Krishnakumar, 2004).

The demand-supply gap for public health care delivery is large and on the rise, and this gap is increasingly being filled by private health care institutions. The urban health care industry is booming, with a host of private hospitals offering state-of-the-art services for the rich and the middle class. A 2002 study, "Health care in India: The Road Ahead" by the Confederation of Indian Industry and McKinsey \& Company, put the total value of the health sector in India at over Rs.1,500 billion or 6 per cent of GDP (Krishnakumar, 2004). Of this, 15 per cent is publicly financed, 4 per cent is financed through social insurance, 1 per cent through private insurance and the remaining 80 per cent is out-ofpocket user-fees. Two-thirds of all users fall into the last category, and 90 per cent of them are from the poorest sections. National data reveal that 50 per cent of the bottom quintile sold assets or took loans to access private hospital care. In fact, nationwide survey of medical expenditure conducted by the National Council of Applied Economic 
Research revealed that, among the poor, expenditure incurred to meet the medical needs is the second most important cause of rural indebtedness (D. Banerji, 2003). An Independent Commission on Health in India, which submitted its report to the former Prime Minister Vajpayee pointed out that the health services are in an 'advanced stage of decay'. Documents from the Planning Commission paint an equally dismal picture (Tenth Five Year Plan, 2004).

\section{India's Health Status}

In the last fifty years India has many achievements in the health sector. All health indicators registered an improvement over time. Nevertheless, their levels are still unacceptable. Even though infant mortality rates have declined from a high of 110 in 1981 to 68 in 2000, it is still very high, vis-à-vis other countries at comparable or even lower levels of development. The fertility rate for India as a whole is 3.2, much above the replacement level. Overall life expectancy at birth has doubled for both males and females between 1941-1951 and 2000: from 32.4 years to 63.3 years for males and from 31.7 years to 65.6 years for females. Although female life expectancy is slightly higher than male life expectancy, achievements along other dimensions of women's health in India are very low. India has one of the highest maternal mortality rates in the world, registering as many as 407 maternal deaths per 100,000 live births in 2000. Another bitter statistic is the lopsided sex-ratio of 927 females per 1000 males, largely due to discrimination against girls and women in nutrition and medical care. Malaria and Tuberculosis claim more than 500,000 lives every year. Added to this is the spectre of AIDS: there are an estimated 4 million HIV positive cases in India and their numbers are expected to grow rapidly. The average figures for India hide a great deal of variation in the performance of different states. While Kerala, Maharashtra and Tamil Nadu are doing 
better, the densely populated states of Orissa, West Bengal, Bihar, Rajasthan, Madhya Pradesh and Uttar Pradesh are way behind.

Health centers in urban area, are generally the populations' first point of contact with any health care personnel. As the bulk of the Indian population lives in rural areas, provision of essential health services through sub-centers and primary health care centers is crucial in determining any access to health care services for most people, especially women and children. All health indicators for rural areas compare unfavorably with those for urban areas; people belonging to scheduled castes and tribes have much poorer health compared to those who belong to the upper castes; and children and women in India suffer grossly from the burden of disease and ill-health. Morbidity among women and children is endemic in India.

In 1982 when the Government reformulated National Health Policy and officially adopted the WHO declaration of "Health for All by 2000", it made many significant changes at the policy level (Chatterjee, 1993). It brought forth the role of community and social sciences in promoting public health care. An apex committee of ICSSR and ICMR was formed to bring changes in the curriculum of medical education and to bring in more input from social science research.

Accordingly, rural health infrastructure development became a major activity in 1980s and a massive expansion of Sub-Health Centres took place with emphasis on maternal and child care, family welfare, and hygiene education. Each PHC was targeted to have one doctor and one community health officer (medical doctor, of course). This expansion was so rapid that the targets of developing infrastructure by 2000 were met in 1991 itself. 
In terms of manpower planning, a remarkable achievement was the training of 4 lakhs of community health workers (CHW) within five years (1977-1982), almost one CHW for each village in the country, constituting the largest health care cadre in the world (Chatterjee, 1993).

These CHWs were trained by medical doctors to take care of common diseases and as a link between the community and medical staff. This rapid expansion did compromise in quality in many ways. Nobody knew what kind of training these CHWs should be imparted and very soon these workers began to perceive themselves as village medical practitioners. Later on, the Indian Medical Association opposed this scheme and termed these CHWs as quacks, who were indeed more popular than the medical doctors in many places. In 1981 when the Government of India transferred this scheme to the states, many states who did not commit to this scheme initially started backing out. Lack of availability of state funds made this scheme almost defunct. These workers were rechristened as Multipurpose Health Workers, and later, as health guides but no serious efforts were made to revive the scheme. The most ambitious scheme of the government lost its direction and relevance in the present time.

In 1990s, a major shift in the national health policy took place in which the management of health was turned over to the local self-government, the panchayati raj. Initially there was a lot of enthusiasm and hope that it will make health services more accountable to local communities. But, like many other schemes, it also got mired in many controversies and rarely showed the desired results. Panchayats in India are not true representative of the people but are dominated by the powerful elite and power brokers. In the feudal 
system that still prevails in rural India, decentralization and bottom-up approach rarely succeed. It is anachronistic to the prevailing ethos and functioning of the Government.

In 2001, the Government announced a new health policy with the main objective of achieving an acceptable standard of good health of the general population. The policy aimed to strengthen the infrastructure, decentralize health care delivery through panchayati raj, setting up national accounting services and to regulate private practice. These were all laudable goals; but no proper mechanism was worked out to implement the provisions of this policy. In fact, this new policy was a kind of rundown for the already depleted primary health centers. The new policy ignored the earlier health policy's objectives of providing primary health care for all, specially to the underprivileged (Quadeer, 2001). The commitment of the earlier policy to create a wellworked out referral system was dumped to make way for privatization and commercialization of health services. The Government opened up the health sector for the private enterprises in a hope that with better monitoring and regulations the private sector will ease resource crunch in the health sector.

The National Rural Health Mission (NRHM) launched by the Union Government in 2004 aimed to rectify the gross neglect of the health care needs of the rural masses. Though the funds allocated for this scheme are paltry (Rs.320 crores), it raises the hope of strengthening health infrastructure, particularly the health worker scheme. It has reconceptualized this scheme as ASHA (Accredited Social Health Activist). The plan is to identify functionally literate women from the same village and train them for awareness building about health rights. In adition, ASHA is expected to implement national health programmes with the support of local panchayats. 


\section{Primary Health Care: Coverage and Quality}

On the 12th of September, 1978, the International Conference on Primary Health Care being held in Alma-Ata, in the erstwhile USSR, adopted the 'Declaration of Alma-Ata' which proclaimed a positive view of health as complete physical, mental and social well being and a fundamental human right. The declaration envisaged primary health care as the first level of contact between individuals and families with their country's health system. According to this declaration, primary health care was to have its basis in the community it served; the notion of primary health care included maternal and child care including family planning, immunization against major infectious diseases, prevention and control of locally endemic diseases, appropriate treatment of common diseases and injuries, provision of essential drugs, education concerning prevailing health problems and ways to deal with them, provision of adequate food and nutrition and adequate supply of clean water. The Declaration of Alma-Ata set a goal for the year 2000 for all the people of the world to achieve a level of health such as to enable them to lead socially and economically productive lives. India, along with other countries, ratified the declaration.

India has a large public health care system. Primary health care is provided through a network of sub-centers, primary health care centers, community health centers and district hospitals. In rural areas, most primary health care is provided either by subcenters or primary health care centers; whereas in urban areas it is provided via health posts and family welfare centers. 
- For the provision of health centers, the Indian government has set the following targets: One sub-center with one trained female and one trained male health worker per 5,000 persons in the plains and per 3,000 persons in hilly and tribal areas.

- One Primary Health Center (PHC) staffed by a medical officer and other paramedical staff per 30,000 persons in the plains and 20,000 persons in hilly, tribal and backward areas. Each PHC is to supervise six sub-centers.

- One community health center (CHC) or upgraded PHC with 30 beds and other basic facilities per $80,000-120,000$ persons. The $\mathrm{CHC}$ is to operate as a referral center for up to four PHCs.

In 1998, there were 137,006 sub-centers, 23,179 PHCs and 2,913 CHCs in India. There were 665,639 hospital beds or 6.9 hospital beds per 10,000 persons. Based on data collected by the National Family Health Survey II 1998-99 (NFHS II), in terms of population coverage, only 13 percent of rural residents had access to a primary health center, 33 percent had access to a sub-center, 9.6 percent had access to a hospital and 28.3 percent had access to a dispensary or clinic. One of the major determinants of the use of a health care facility, when it exists, is the distance to the location of the facility from the user's home. This is especially true for women and children in rural areas. Overall, 47.4 percent villages had access to any health facility within their village and 38.9 percent villages had access to any facility within less than five kilometers. According to the Fifteenth Human Development Report (1999), in India only 22 percent of villages had a sub-center within their village based on the population criteria. Coverage varies across Indian states. In Bihar, Orissa and Punjab, the proportion of villages with sub-centers was as low as 5-6 percent; less than 30 percent of villages had 
access to a primary health care center or hospital in Bihar, Gujarat and Madhya Pradesh. There was better coverage quantitatively in Tamil Nadu with 50 percent villages having access, and in Maharashtra and Haryana, between 30-36 percent. Tamil Nadu, Kerala and Karnataka also had greater access to a hospital within five kilometers of the place of residence (Human Development Report India, 1999).

Apart from the number of health centers providing primary health care, the availability of primary health care also depends on the number of doctors, nurses and other medical personnel positioned in these centers. The public health system in India faces a critical problem of staff shortage, especially in rural areas, as medical personnel in general do not want to be locate in rural and remote areas. As a result many posts in sub-centers and PHCs in rural areas remain vacant. For example, in 1996, as many as 4,281 of 29,699 doctors posts sanctioned remained unfilled in rural health institutions (Misra et al., 2003). Thus, the existing extensive network of public health centers falls far short both in terms of population coverage and the guidelines set out by the government. As the poor are the main users of primary health care facilities, the rich preferring to use private clinics and hospitals, the absence of public primary health care services means that many people either forego any medical care altogether or use too little too late or choose to seek expensive and unregulated care in the private sector.

In India, the quality of health care services provided by the public health system is extremely low almost along all the criteria on which quality can be judged infrastructure, availability of drugs and equipment, regular presence of qualified medical personnel and treatment of patients. Instead of being supportive and palliative of people's health, it will not be remiss to say that the health system itself poses a hazard to its 
intended beneficiaries, especially the poor, who are often as reluctant to use public health services as the rich.

Quality of health care services provided can be assessed along the following dimensions (which are by no means exhaustive): (1) an adequately equipped and easily accessible public health facility, (2) appropriate and timely clinical care, and (3) patient satisfaction with health care received and the outcome of treatment. Ultimately, the real test of the quality of health care services is how they affect health outcomes, especially of the poor.

Bajpeyi (2004) has extensively reviewed the quality of primary health care services along some criteria. At the least, a primary health care service center should have the following in terms of infrastructure: the building in which it is housed to be in good condition; availability of electricity and running water; the presence of a telephone or some means of communication for situations where ambulatory and emergency care may be required.

One of the major lacunae in India's health system is lack of quality control. There is little public enforcement to ensure appropriate standards of care in clinical practices. This is as true of the public sector as of the private sector which is largely unregulated. The Medical Council of India, the main body overseeing standards of care, has no process in place whereby doctors are assessed, as to their competence with respect to current standards of care when they renew their registration. Given the lack of effective monitoring, there is little information to go by in terms of competence of medical personnel and actual practice in clinical settings, though there is some evidence of overuse of antibiotics and tranquilizers in public health care centers. 
Delivery of public health care services in India is marked by pervasive absenteeism. According to one study, absenteeism among doctors was as high as 43 percent and among other health workers, 39 percent in government health care facilities across Indian states (Chaudhury et al, 2003). A survey conducted by Banerjee (2003) in Udaipur in Rajasthan, found greater absenteeism in PHCs and CHCs than in sub-centers. This meant that for people seeking health care services, there was considerable uncertainty attached to a visit that is costly in terms of time and money, whether they would find it open and if open, finding someone there. Such uncertainty further attenuates people's incentives to make use of public health facilities. Under the family welfare program, health or family planning workers are required to make regular visits to each household in their area of assignment to monitor women and children's health, provide family planning information and counsel and deliver selected services. Only 13 percent of women in India, according to the NFHS II, reported receiving a visit from a health or family planning worker in the last 12 months preceding the survey.

One notable failure of most of the rural health programmes is low community participation. Imposed from outside by the government functionaries and NGOs, these programmes could not garner community support. Western and westernized NGOs are incompatible with local culture, and needs and aspirations of people. Rarely local health practices and resources were taken cognizance of, nor the services of traditional practitioners were acknowledged. 


\section{Traditional Health Care Services: A Paradox}

Parallel systems of health care existed in India for ages. Traditional health care practices are of two types. The first can be loosely categorized as faith and folk practioners, which comprises shamans, mystics, tantriks, faith healers, priests, ojhas, yogis, gurus, babas and others. Though these healing practices are consistent with the cultural beliefs and have popular mass support, these are seen with skepticism by most of the government agencies. The second category which is often labeled as traditional medicine and recognized by the government as alternative systems are the practitioners of ayurveda, Yunani system and homeopathy. Of course there are many others, such as herbal practitioners, naturopaths, acupuncturists, etc, who are frequented by patients and their families. Such a diversity of systems and their local variants constituted a rich tapestry of health care practices in India. They provided the whole range of services to cater to physical, mental, social and spiritual health of local communities. It may be noted that most of these practices and associated systems have evolved over a long history - some of these have been practiced for thousands of years, are time-tested and culturallycompatible (Dalal \& Subha, 2005). These practices survived primarily on popular support and being integral to community life. WHO estimated that, "In many countries, $80 \%$ or more of the population living in rural areas are cared for by traditional practitioners and birth attendants."(Bodekar, 2004).

The statistics show that India, has about 380,000 practitioners of traditional medicines(1 per 2200 population). Besides, there are large number of folk health practitioners, ranging from fait healers to hydro-therapists. If 400,000 medical practitioners are added to this figure, India has one of the best patient-practitioner-ratio in the world. India's policies on indigenous medicine could go a long way in meeting the health needs of the masses. 
These enormous resources have not been systematically utilised by the health planners so far. The most unfortunate part is that due to official neglect and dominance of modern medicine, traditional practices are in shambles. The worst victims of this official apathy are those rural poor who otherwise have no access to modern medicine.

\section{The Challenge of Integrating Health Care Systems}

To understand the real challenge of integration of diverse systems, let us briefly review the genesis of the conflict. In 1938, largely as a result of the Freedom Struggle and emphasis on 'swadeshi', the National Planning Committee (NPC) set up by the Indian National Congress took a decision to absorb practitioners of Ayurveda and Yunani systems into the formal health set-up of independent India. In 1946, the Health Ministers' Conference adopted the NPC proposals and resolved to make appropriate financial allocations for:

(a) research, based on the application of scientific methods, in Ayurveda and Yunani;

(b) the establishment of colleges and schools for training in diploma degree courses in indigenous systems;

(c) the establishment of postgraduate courses in Indian medicine,

(d) the absorption of vaids and hakims as doctors, health workers etc, and

(e) inclusion of departments and practitioners of Indian medicine on national health committees.

As a result of the Conference resolutions, the government set up the Chopra Committee (1948) on the Indigenous Systems of Medicine to work out guidelines for the implementation of the above proposals. The Chopra Committee eventually came out in support of a synthesis of the Indian and Western systems through integrated teaching and 
research. It recommended that the curriculum be designed to strengthen and supplement one system with the other, with each making up for the other's deficiencies, while research should be concentrated on removing useless accretions to Ayurveda and making it intelligible to modern minds since a large portion of the texts were in Sanskrit. The ultimate objective of the research ought to be a synthesis of Indian and Western medicine which was suited to Indian conditions.

The Chopra Committee was followed by the Dave Committee which went into the issue of establishing standards in respect of education and regulation of practice in ISM. The Committee recommended an integrated course of teaching and some states in the Indian Union in fact started integrated colleges which taught both modern medicine and Ayurveda. In other states, however, pure Ayurveda colleges were also established. Indeed, the political and market forces were not favourable for any integrated approach. The medical practitioners who dominated health care services were not ready to dilute their education and practices to accommodate traditional practices.

As a consequence, the support for integrated medical colleges declined while pressure for pure Ayurvedic colleges increased. Ayurvedic practitioners and supporters of ayurveda generally pointed to the popularity of indigenous practitioners; the higher cost of integrated colleges due to the expensive equipment required to teach Western medicine; the tendency to spend too much time on allopathy; the availability of indigenous graduates for rural practice, and finally, the inherent incompatibility of the two systems. Eventually, the supporters of a pure system of education and training for Ayurveda, homeopathy and Yunani system gained political support in the country's political circles. This led to the formation of several independent Councils for looking after the research, 
development, training and regulatory aspects relating to ISM. However, it we look in terms of funding support, ISM always got ridiculously low funding out of the total health allocation. In the First Five Year Plan (1952-57) the total allocation for ISM was about 1 per cent of the total health budget; it increased marginally in subsequent plans, but came down to 1.3 per cent in the Seventh Plan (1985-90). The total allocation was raised from Rs 35 crores last year to Rs 100 crores in the year 2004, and this announcement drew applause from the starved ISM sector. It is appropriate to mention here that the total allocation for the Ministry of Health the same year was Rs. 4319 crores, and ISM got a mere $2.5 \%$ of the whole budget. This is a clear indication of the marginalisation of the Indian systems of medicine in the public health care system (M.Banerji, 2004).

WHO which primarily relied on the medical model of health care blatantly promoted western medicine in developing countries, at least for the first two decades of its existence. In the Alma-Ata Conference (1977), to achieve the goal of Health for All by 2000 , it recommended that governments give high priority to the utilization of traditional medicine practitioners and traditional birth attendants and incorporate proven traditional remedies into national drug policies and regulations. Of course, most of the countries, including WHO, only paid lip service to this stated goal. The present resurgence of traditional medicines is outside the aegis of WHO and other international agencies, including national governments. It seems to be a logical consequence of the failure of modern medicine (Banerji, 2003).

Presently there are more than 200,000 registered traditional medical practitioners in India and over a hundred degree-granting colleges of Ayurvedic education. Besides, there are one million homeopathic practitioners while some 220 colleges turn out around 9,000 
graduates in ISM every year. As per the 1994 estimates, India has almost 240,000 registered Ayurvedic practitioners, 12,000 Ayurvedic dispensaries, 1,452 hospitals and 100 postgraduate colleges. As for research into ISM, the government first set up the Central Council for Research in Indian Medicine and Homeopathy in 1969. The Council guided and supervised research through its five technical advisory boards. This body, however, was dissolved in 1979. In its place, the government decided to set up Central Councils along the lines of the Indian Council for Medical Research.

\section{The Possibilities of Integration}

There are two schools of thoughts in this regard. The first school views traditional systems as based on fundamentally different assumptions about human life, health and illness, which, in no way can reconcile with the theories of biomedicine. The traditional medicines attempt to restore the balance of mind-body-soul and treat patients holistically. The medical approach, on the contrary, treats a patient as a passive organism and focuses only on bodily aspects of the health problem. These fundamental differences in these two approaches are reflected in the differences in the formulation of the theories pertaining to causation of diseases, pharmacology and drug action, dietetics and nutrition, diagnostics, etc. (Shankar, 1992). Thus, those who subscribe to the first school consider western and traditional medicines irreconcilable and prefer them being practiced rather independently.

The second school though acknowledges the differences in the two medicinal approaches, they see many possibilities of developing a unified health care delivery system. Their emphasis is on a creative synthesis between these two systems to develop a new Indian model of health care. The vast local resources of health care need to be mobilized into the crumbling public health services where different medicinal systems can work under one 
roof. There are many possibilities and we need to learn from the experiments done in many Asian countries.

Sri Lanka has the health care practices which is a good example of possible integration at the level of service delivery. There, all systems are allowed to practice freely but an enquiry is mandatory if there is any casualty of suspicious nature. This enquiry is conducted by a group of respectable local people. Because of this practice many folk practitioners refer serious cases to medical doctors, as cases of psychogenic illnesses are referred by medical practitioners to local healers. Such formal collaboration between modern and traditional medical sectors can grow to meet all health eventualities. Sri Lanka has very developed legislative and policy frameworks for the promotion and development of traditional medicine. It has a separate Ministry of Ayurveda for the last four decades, something which India did much later. Sri Lanka, with its meager resources, has evolved one of the best health care system in Asia and has achieved health targets almost on par with the western standards.

The health care system needs to be made more broad-based, so that it can handle all the facets of the problem, including public education about health and hygiene. Apart from providing curative services, rural health centres should have been the nucleus of all-round development. To achieve this dream, it is important that social workers, school teachers, religious leaders, and even faith healers are closely associated with the activities of the health centres. Indonesian health services have shown the way, where traditional healers are trained to refer serious cases to medical professionals, but these patients come back to the traditional healer for holy water, once they were cured (Pareek, ). This system, thus, 
not only relieves pressure on the medical practitioners, but also takes care of both curing and healing aspects of the disease.

A modest beginning in the direction of integration can be made at the level of community health workers (CHWs). These health workers can be trained to be an important link between various schools of health care providers. The CHWs can be suitably trained to map and utilize local health resources. If the local healers who are respected and trusted by the villagers can be identified and trained in holistic health practices, they can provide the first level services. He/she may assist the Panchayat in meeting the basic health needs and act as a strong link between the Health Agencies and local people. In addition, there should be a massive effort in health education in the entire country, through school teachers, panchayat members, youth clubs, Mahila Mandals and community development workers to help people inculcate a more rational and scientific understanding of both traditional medicine and public health issues. In this, national networks of voluntary organisations can play an important role.

While discussing the possibilities of integration of ISM at the level of primary health care we need to be wary of some new trends emerging in the global market. The market requirement of standardisation, commercialisation and pharmaceuticalisation of the medicine has substantially changing profile and practices of the ISM in the arena of health. There is an apparent paradox. While these processes have conferred a new legitimacy on traditional systems, their radical transformation has meant that even as their face-value has appreciated, their innate importance as systems of healing has declined. Indigenous medicine are in danger of falling prey to pharmaceuticalisation, i.e., using the pharmacology of these systems to create new pharmaceuticals, or medicinal 
commodities, that could be sold independently of the original line of treatment ( Nandy \& Visvanathan, 1990). Such commodification of indigenous systems may give a false impression that it's popularity is on increase, but in essence it could be allopathization of the Indian systems. Thus, while getting integrated within the primary health care, it is equally important that Indian systems of medicine preserve their -humanistic-holistic character.

\section{References}

Banerjee, M. (2000). Whither indigenous medicine. http://www.indiaseminar.com/2000/489.html.

Banerji, D. (2003). Primary health care in India: An overview. Guest Lecture at the National Seminar on Health For All in the New Millenium, NIHFW, New Delhi, February 24-26.

Bodeker G. C. (1999). Traditional (i.e. indigenous) and complementary medicine in the Commonwealth: new partnerships planned with the formal health sector. Journal of Alternative Complementay Medicine, 5, 97-101.

Bodeker, Gerard C. (2004). Traditional health systems and national policy. http://users.ox.ac.uk/ gree0179/

Chatterjee, M. (1993). Health for too many: India's experiments with truth. In Rohde, J., Chatterjee, M, \& Morley, D. (Eds.), Reaching health for all. New Delhi: Oxford University Press. 
Dalal, A.K., \& Subha, R. (2005). Social dimension of health and well-being: An overview of research trends. In Dalal, A.K., \& Ray, Subha (Eds.), Social Dimensions of Health. Jaipur : Rawat

Human Development Report (1999).

Krishnakumar, A. (2004). An unhealthy trend. Frontline, 21(24), November 20December.3.

Kumar S. (2000). India's government promotes traditional healing practices. Lancet, 335, 1252.

Ministry of Health, Report of the Committee on Indigenous Systems of Medicine (Chairman: Sir R.N. Chopra), New Delhi, 1948.

Ministry of Health, Report of the Health Survey Committee (Chairman: Sir R.N. Bhore), New Delhi, 1946.

Nandy, A. and Visvanathan, S.(1990). Modern medicine and its non-modern critics. In F.A. Marglin and S. Marglin (Eds.), Dominating Knowledge: Development, Culture and Resistance. Oxford: Clarendon Press.

Planning Commission of India (1952). First FiveYear Plan (1952-1957), New Delhi: Government of India.

Planning Commission of India (1992). Fifth Five Year Plan (1992-97). New Delhi: Government of India. 
Planning Commission of India (2001). Approach Paper to the Tenth Five Year Plan (2002-2007). New Delhi: Government of India.

Qadeer, I. (2001). Debt payment and devaluating elements of public health. Economic and Political Weekly, 37(1), 12-16.

Shankar, D. (1992). Indigenous health services: The state of the art. In A. Mukhopadhyay (Ed.). State of India's health. New Delhi: Voluntary Health Association of India.

Shankar, D. (1992). Indigenous health services: The state of the art. In A. Mukhopadhyay (Ed.). State of India's health. New Delhi: Voluntary Health Association of India. 